\title{
The prevalence of urethral and rectal Mycoplasma genitalium among men who have sex with men in China, a cross-sectional study
}

\author{
Bing-jie Zheng ${ }^{1}$, Yue-ping Yin ${ }^{2 *}$, Yan Han ${ }^{1}$, Mei-qin Shi ${ }^{1}$, Ning Jiang ${ }^{1}$, Zhi Xiang ${ }^{1}$, Rui-xing Yu ${ }^{1}$, Guo-yi Zhang
} and Xiang-sheng Chen ${ }^{1}$

\begin{abstract}
Background: Although Mycoplasma genitalium (MG) is a common sexually transmitted infection (STI), very little information regarding the prevalence of MG among MSM (men who have sex with men) is available in China. The objective of this study was to determine the prevalence of MG among MSM in the city of Shenzhen, Guangdong Province, China, and to identify the potential risk factors associated with MG infection in this population.

Methods: Between January and May 2010, a total of 409 MSM were recruited in Shenzhen, Guangdong Province, China. An anonymous questionnaire was used to collect information regarding their sociological and sexual behaviors. In addition, their first-void urine (FVU) samples and rectal swabs were collected for PCR-based MG testing.

Results: Among the $406 \mathrm{FVU}$ and 405 rectal swab samples were collected from 409 MSM, the overall MG prevalence was $8.1 \%$ (33/406, 95\% Cl 5.7\%-10.6\%), with a FVU positivity of 3.4\% (95\% Cl 1.7\%-5.4\%) and a rectal positivity of 5.4\% (95\% Cl 3.5\%-7.7\%). Using both univariate and multivariable logistic regression analyses, urethral MG infection was significantly associated with having more heterosexual behaviors (AOR 7.16,95\% Cl 1.89-27.13), and with having unprotected anal intercourse in the past six months (AOR 4.80, 95\% Cl 1.40-16.47). Rectal MG infection was significantly associated with HIV infection based on univariate logistic regression analysis $(\mathrm{OR}=4.49,95 \% \mathrm{Cl}$ 1.18-17.12).

Conclusions: In this study, we investigated the prevalence of MG infection in the population of interest, as determined from both urethral and rectal specimen. We showed that MG was more prevalent in MSM who had bisexual behaviors compared to those who engaged only in homosexual behaviors. Further work is needed to establish the mode of MG transmission and to identify its role in HIV transmission. Meanwhile, more attention should be paid to MG infection among MSMs, and especially bisexual MSMs, which might have critical implications for effective HIV/STD control in China.
\end{abstract}

Keywords: Mycoplasma genitalium, Prevalence, MSM, China

\section{Background}

Accumulating evidence supports that Mycoplasma genitalium (MG) is a common sexually transmitted infection (STI) pathogen that can cause non-gonococcal urethritis (NGU) in men [1-3] and pelvic inflammatory disease (PID) in women $[4,5]$. In addition, the positive association between MG and human immunodeficiency virus (HIV) has been identified in several studies [6-8]. However, there have been limited number of epidemiological studies on MG infection worldwide and data on the

\footnotetext{
* Correspondence: yinyp@ncstdlc.org

${ }^{2}$ Reference Laboratory, 12 Jiangwangmiao Street, Nanjing 210042, China

Full list of author information is available at the end of the article
}

prevalence of this pathogen among men who have sex with men (MSM) are especially scarce. MSM is a critical population because it plays a significant role in the spread of HIV and other sexually transmitted diseases (STD) [9]. Recent studies revealed an increasing trend of HIV/STD prevalence in Chinese MSM [10]. However, to date, there have been no reports on the prevalence of MG in this population. As part of a large cross-sectional research effort aimed at investigating the epidemiology of MG infection among high risk populations in China, this study has two objectives: (i) to determine the prevalence of urethral and rectal MG in MSM in Shenzhen, 
Guangdong Province, China, and (ii) to identify the potential risk factors for MG infection.

\section{Methods \\ Participants}

Between January and May 2010, a total of 409 men older than 18 years old who reported having oral sex or anal sex with men within the past year were recruited for this study. Participants were recruited from a MSM voluntary counseling and testing clinic in Shenzhen, China. This clinic has been operated by a non-governmental organization (NGO) and the local center for disease control (CDC). Those who participated in high-risk behaviors (e.g. MSMs) were generally willing to undergo free counseling and HIV/STD testing at this clinic. Meantime, a free and confidential physical exam was provided if the patient desired. After informed consent was obtained, each participant was asked to fill out an anonymous questionnaire containing questions regarding socio-demographic characteristics, sexual behaviors and STD history information in a private room on his own. After completing the questionnaire, all participants accepted a routine physical examination by a trained doctor according to the standard protocol. Approximately 10-15 ml of FVU samples were collected by the participants themselves, and rectal swabs were collected by trained nurses. The specimens were kept at $-20^{\circ} \mathrm{C}$ until sample collection from all participants was completed. The specimens were then sent to the National Center for STD Control in Nanjing, China on dry ice by a cold-chain transportation. Those who declined to provide either urine or rectal specimens were included in the analysis as unpaired data. The protocols for this study were reviewed and approved by the Medical Ethics Committee at the Institute of Dermatology of the Chinese Academy of Medical Sciences. This study was nested within a multisite cross-sectional screening program investigating the prevalence of STIs and HIV infection among MSMs [11]. Therefore, test results regarding the participants' HIV positivity were also available to us. We took advantage of these data to analyze the association between MG and HIV infections.

\section{Laboratory test}

After arrival in the laboratory of National Center for STD Control in Nanjing, China, rectal swab specimens were eluted with $500-\mu \mathrm{l}$ normal saline. Each urine specimen and rectal swab eluent was mixed thoroughly, distributed into aliquots and stored at $-70^{\circ} \mathrm{C}$ until tested for MG. Genomic DNA was extracted from the specimens by QIAmp DNA Mini Kit (Qiagen $\mathrm{GmbH}$, Germany) according to the manufacturer's protocol. MG DNA was detected using a previously published real time PCR method that targets the $\mathrm{MgPa}$ adhesion gene [12,13].

\section{Data analysis}

Data were independently entered into a computer database using EpiData software (EpiData Association, Denmark) by two research assistants, and any discrepancies were resolved prior to analysis. Statistical analyses were performed using SPSS for Windows 13 (SPSS, Inc, Chicago, IL, USA). Comparisons of categorical variables were conducted using a chi square test. Univariate analyses were performed to examine the relationships between each variable and MG infection. Only variables that were significant in the univariate analyses with $\mathrm{P}$ values $<0.10$ were included in multivariable logistic regression models for selecting independent risk factors. Odds ratios (ORs) and their corresponding 95\% confidence intervals (CIs) were calculated.

\section{Results}

Between January and May 2010, a total of 409 MSMs were recruited in this study; of them, three declined to provide FVU and four others declined to provide rectal specimens. Thus, 406 urine samples and 405 rectal swabs were collected for detection of MG.

\section{Demographic and behavioral characteristics}

The mean age of MSM participants was 30.5 years old (ranging 18-64 years), and more than half of them were younger than 30 years old. The majority of participants were of Han ethnicity $(95.6 \%, 391 / 409)$; 64.5\% (264/409) received senior high school or lower education; $75.1 \%$ (307/409) were single, divorced, or widowed; 23.7\% (97/ 409) were permanent residents of Guangdong province, China; $45.5 \%$ (186/409) were living alone.

Our results showed that $34.3 \%(134 / 390)$ of participants identified themselves as homosexual men and $61.5 \%(240 / 390)$ of participants reported having sexual intercourse only with men or more with men than with women. Overall, 93 (22.9\%) of MSMs engaged in commercial sexual behaviors and $96.7 \%$ (90/93) of them used condoms during the most recent commercial sex encounters. 386 MSMs reported having anal sex in the past 6 months, of which 275 did not use condoms. Additionally, 106 (26.1\%) participants reported having sex with women during the past six months, and 23 (5.6\%) reported using illegal substances in the past year.

\section{MG test results and risk factors}

Of the total $406 \mathrm{FVU}$ and 405 rectal samples processed, 14 (3.4\%, 95\% CI 1.7\%-5.4\%) FVU samples and 22 (5.4\%, 95\% CI 3.5\%-7.7\%) rectal samples were positive for MG DNA by real-time PCR method. Three pairs of urine and rectal specimens were co-positive for MG, giving an overall MG prevalence of $8.1 \%$ (33/406, 95\% CI 5.7\%-10.6\%).

Analyses of MG test results from the urethral samples suggest that attendees who engaged in predominantly 
heterosexual behaviors were nearly five times more likely to be infected with urethral MG than those who were predominantly homosexual (OR 4.56, 95\% CI 1.31-15.90, $\mathrm{P}=0.017$ ). In addition, having unprotected anal intercourse in the past six months was significantly associated with positive urethral MG (OR 3.53, 95\% CI 1.19-10.41, $\mathrm{P}=0.023$ ). Multivariate analyses revealed that urethral MG infection was significantly associated with having more heterosexual behaviors (AOR 7.16, 95\% CI 1.8927.13, $\mathrm{P}=0.004$ ) and with unprotected anal intercourse (AOR 4.80, 95\% CI 1.40-16.47, P = 0.013) (Table 1).

Analyses of MG test results from the rectal samples suggest a significant association between rectal MG and HIV infection, with an OR of 4.49 (95\% CI 1.18-17.12, $\mathrm{P}=0.028$ ) (Table 1).

We did not find significant associations between overall MG infections and any demographic factors, urethral or rectal symptoms, self-identified sexual orientation, and commercial sex behaviors. No significant correlation was observed between overall MG and HIV infections (OR 2.79, 95\% CI 0.75-10.86, $\mathrm{P}=0.124$ ) although the prevalence of MG was higher in HIV-positive attendees (18.7\%) than in HIV-negative attendees (7.6\%). In addition, of those three participants with dual MG positivity in FVU and rectal specimens, one was co-infected with HIV (Table 2).

\section{Discussion}

There are a few reports on the prevalence of MG infections among MSM populations in both urine and rectal specimens [14-16]. Among MSMs in London, the overall MG prevalence was $6.6 \%$ with $2.7 \%$ positive in FVU and $4.6 \%$ positive in rectal specimens [15]. A cross-sectional study of 521 MSMs in Melbourne reported these rates to be $2.1 \%, 0.6 \%$, and $1.6 \%$, respectively [14], and Reinton et al. reported 5.1\%, $1.7 \%$ and $4.5 \%$, respectively, in the studied population of Norway [16]. Our present study found that MSMs in Shenzhen, China had an overall MG infection rate of $8.1 \%$, with $3.4 \%$ positive in FVU and $5.4 \%$ positive in rectal specimens. Compared to the abovementioned studies, this study showed higher prevalence of overall MG infection as well as in both anatomic sites. Given that MG prevalence of male STD attendees and female sex workers (FSWs) in the studied area were higher than in other countries [13], the high prevalence in this study may indicate a MG epidemic in this region. In addition, regardless of differences in MG detection method and MG prevalence in different areas, all studies have found that MG was more likely to be detected in the rectal specimens than in FVU in the MSM population, indicating that anorectal mucosa might be easily infected with MG in the population who had anal sex. Interestingly, the same phenomenon has been frequently reported in studies on the epidemiology of CT infection among MSMs, with $4.0 \%-7.9 \%$ positive in rectal specimens and $1.5 \%-5.2 \%$ positive in urethral specimens $[14,17-20]$. These studies also found that rectal CT infections were more asymptomatic than urethral infections. However, it is not clear whether rectal MG infection is also asymptomatic compared to urethral infection. Regardless of whether rectal MG infection is asymptomatic, or whether anorectal mucosa is easily infected, it is becoming clear that the rectum is a core anatomic site for both MG and CT infections in the MSM population. Currently, the Centers for Disease Control (CDC) guidelines recommend that STD clinics offer CT rectal screening or diagnostic testing, but have not given a similar suggestion for MG, and few STD clinics perform routine screening of rectal or urethral MG for urethritis/proctitis patients or asymptomatic patients. Considering the higher prevalence of rectal MG infection,

Table 1 Risk factors associated with urethra/rectum MG infection

\begin{tabular}{|c|c|c|c|c|}
\hline Characteristic & $\begin{array}{l}\text { Percentage with } \\
\text { characteristic }\end{array}$ & $\begin{array}{l}\text { MG infection } \\
\text { number (\%) }\end{array}$ & $\begin{array}{l}\text { Crude odds ratio } \\
(95 \% \mathrm{Cl}), \mathrm{P} \text { value }\end{array}$ & $\begin{array}{l}\text { Adjusted odds ratio } \\
(95 \% \mathrm{Cl}), \mathrm{P} \text { value }\end{array}$ \\
\hline \multicolumn{5}{|l|}{ Urethral MG } \\
\hline \multicolumn{5}{|l|}{ Sexual partners } \\
\hline Only men or predominantly men & $346(89.4)$ & $8(2.3)$ & 1 & \\
\hline Almost equally or predominantly women & $41(10.6)$ & $4(9.8)$ & $4.57(1.31-15.90), 0.017^{*}$ & $7.16(1.89-27.13), 0.004$ \\
\hline \multicolumn{5}{|l|}{ Unprotected anal intercourse in the past 6 mo } \\
\hline No & $273(71.5)$ & $6(2.2)$ & 1 & \\
\hline Yes & $109(28.5)$ & $8(7.3)$ & $3.53(1.19-10.41), 0.023^{*}$ & 4.80 (1.40-16.47), 0.013 \\
\hline \multicolumn{5}{|l|}{ Rectal MG } \\
\hline \multicolumn{5}{|l|}{ HIV Infection } \\
\hline Yes & $16(4.0)$ & $3(18.8)$ & $4.49(1.18-17.12), 0.028$ & \\
\hline No & $389(96.0)$ & $19(5.1)$ & 1 & \\
\hline
\end{tabular}

*included in multivariable analysis. 
Table 2 Risk factors associated with overall MG infection

\begin{tabular}{|c|c|c|c|c|}
\hline Characteristic & Number (\%) with characteristic & MG infection number (\%) & Crude odds ratio $(95 \% \mathrm{Cl})$ & $P$ value \\
\hline \multicolumn{5}{|l|}{$N=409$} \\
\hline \multicolumn{5}{|l|}{ Age in years } \\
\hline$\leq 30$ & $233(57.0)$ & $20(8.6)$ & $1.18(0.57-2.44)$ & 0.660 \\
\hline$>30$ & $176(43.0)$ & $13(7.4)$ & 1 & \\
\hline \multicolumn{5}{|l|}{ Ethnicity } \\
\hline Han & $391(95.6)$ & $32(8.2)$ & $1.52(0.20-11.76)$ & 0.691 \\
\hline Other & $18(4.4)$ & $1(5.6)$ & 1 & \\
\hline \multicolumn{5}{|l|}{ Education } \\
\hline Senior high school or lower & $264(64.5)$ & $24(9.1)$ & $1.51(0.68-3.34)$ & 0.308 \\
\hline Junior college or higher & $145(35.5)$ & $9(6.2)$ & 1 & \\
\hline \multicolumn{5}{|l|}{ Marital status } \\
\hline Unmarried & $307(75.1)$ & $26(8.5)$ & $1.26(0.53-2.99)$ & 0.606 \\
\hline Married & $102(24.9)$ & $7(6.9)$ & 1 & \\
\hline \multicolumn{5}{|l|}{ Residential status } \\
\hline Guangdong Province & $97(23.7)$ & $5(5.2)$ & 1 & \\
\hline Other Province & $312(76.3)$ & $28(9.0)$ & $1.81(0.68-4.83)$ & 0.234 \\
\hline \multicolumn{5}{|l|}{ Cohabiting status } \\
\hline Living alone & $186(45.5)$ & $18(9.7)$ & $1.09(0.45-2.60)$ & 0.855 \\
\hline Living with spouse or family & $73(17.8)$ & $2(2.7)$ & $0.29(0.06-1.39)$ & 0.120 \\
\hline Living with men & $61(14.9)$ & $5(8.2)$ & $0.90(0.28-2.91)$ & 0.866 \\
\hline Living with women or others & $89(21.8)$ & $8(9.0)$ & 1 & \\
\hline \multicolumn{5}{|l|}{ Presenting STI symptoms in the past year } \\
\hline Yes & $35(8.6)$ & $5(14.3)$ & $2.06(0.74-5.72)$ & 0.166 \\
\hline No & $374(91.4)$ & $28(7.5)$ & 1 & \\
\hline \multicolumn{5}{|l|}{ Sexual orientation } \\
\hline Homosexual only & $134(34.4)$ & $10(7.5)$ & $0.57(0.11-2.84)$ & 0.488 \\
\hline Bisexual (homosexual predominance) & $240(61.5)$ & $18(7.6)$ & $0.57(0.12-2.69)$ & 0.476 \\
\hline Bisexual (heterosexual predominance) & $16(4.1)$ & $2(12.5)$ & 1 & \\
\hline \multicolumn{5}{|l|}{ Sexual partners } \\
\hline Only men or predominantly men & $349(89.4)$ & $26(7.4)$ & 1 & \\
\hline Almost equally or predominantly women & $41(10.5)$ & $4(9.8)$ & $1.34(0.44-4.06)$ & 0.601 \\
\hline \multicolumn{5}{|l|}{ Commercial sex work } \\
\hline Sometimes & $93(22.9)$ & $5(5.4)$ & $0.58(0.22-1.54)$ & 0.274 \\
\hline Never & $313(77.1)$ & $28(8.9)$ & 1 & \\
\hline \multicolumn{5}{|l|}{ Anal intercourse in the past 6 mo } \\
\hline Yes & $386(95.1)$ & $32(8.3)$ & $1.72(0.22-13.25)$ & 0.604 \\
\hline No & $20(4.9)$ & $1(5.0)$ & 1 & \\
\hline \multicolumn{5}{|l|}{ Unprotected anal intercourse in past 6 mo } \\
\hline No & $275(71.4)$ & $20(7.3)$ & 1 & \\
\hline Yes & $110(28.5)$ & $12(10.9)$ & $1.56(0.74-3.31)$ & 0.246 \\
\hline \multicolumn{5}{|l|}{ Vaginal sex in the past 6 mo } \\
\hline Yes & $106(26.1)$ & $5(4.7)$ & $0.48(0.18-1.28)$ & 0.141 \\
\hline No & $299(73.8)$ & $28(9.4)$ & 1 & \\
\hline
\end{tabular}


Table 2 Risk factors associated with overall MG infection (Continued)

\begin{tabular}{llll}
\hline Place for seeking sexual partners & & $10(5.6)$ & $0.53(0.25-1.15)$ \\
Non-internet & $177(43.3)$ & $23(10.1)$ & 1 \\
Internet & $228(55.7)$ & & 0.110 \\
Illegal substance use in the past year & & $1(4.3)$ & $0.50(0.07-3.80)$ \\
Yes & $23(5.7)$ & $32(8.4)$ & 1 \\
No & $381(93.2)$ & & $2.79(0.75-10.34)$ \\
HIV Infection & $16(3.9)$ & $3(18.7)$ & 1 \\
Yes & $393(96.7)$ & $30(7.6)$ & 0.496 \\
No & & & 0.124 \\
\hline
\end{tabular}

identifying the populations with rectal infection is a key component of successful MG surveillance and control among MSMs.

In the present study, MG was more common among HIV-infected individuals (18.7\%) as compared to those without HIV infection (7.6\%), but the difference was not statistically significant. This is consistent with previous studies among male NGU patients, which also showed insignificant correlation between these two pathogens $[21,22]$. Notably, we found that the risk of rectal MG infection was significantly higher (5 times) in MSMs who had an HIV infection compared to those who did not have an HIV infection. However, the risk of urethral MG infection only doubled with HIV infection and the difference was not statistically significant. This discrepancy in MG and HIV association might in part reflect the sexual behaviors of these high risk populations: compared with the general population, HIV-positive men are more likely to change sexual partners frequently and more likely to have unprotected anal sex $[23,24]$. On the other hand, immunosuppression and T-cell dysfunction caused by HIV could increase the susceptibility to MG [25]. Savio et al. reported that MG was more commonly detected among acquired immune deficiency syndrome (AIDS) patients compared to those asymptomatic, HIVpositive individuals [26]. Meanwhile, the potential acute or chronic inflammation of rectal mucosa caused by MG may also play a role in HIV infection. However, to date, it is unclear whether the increased risk of HIV infection is due to MG infection. Previous longitudinal studies reported over two-fold higher risk of HIV acquisition by women infected with MG than by those without MG, and $8.7 \%$ of HIV-1 acquisition were attributable to prior MG infection [27]. Further research is needed to establish the causal relationship between MG and HIV infections.

At present, the MSM population has become one of the high-risk groups for HIV/STD infection because of their active sexual activities without protection [9]. According to a systematic review and meta-analysis on HIV incidence among MSMs in China, about 33\% of new HIV cases in 2009 occurred in MSMs who account for only $2-4 \%$ of the Chinese adult male population [28]. More attention has been paid to this population in preventing HIV/STD transmission. However, the main focus has been on preventing syphilis and other STIs, while little effort has been devoted to MG detection and prevention. Our results showed an association between HIV and MG infections, which might highlight the importance of testing of MSMs for MG, especially in the rectum.

Notably, we have found that MSMs who engaged in predominantly heterosexual behaviors were more likely to be infected with urethral MG than those who were predominantly homosexual. This result is similar to findings from previous studies among male STD patients $[29,30]$. This might be attributed to more unprotected vaginal and anal intercourses in this population than in MSMs who engaged in exclusively homosexual behaviors. Several studies have reported that urethral MG infection was associated with unprotected vaginal sex $[2,30]$. The prevalence of MG infection in FSWs and heterosexual men, ranging from $12 \%$ to $26 \%$ [17,31-33], was higher than that in MSMs, from $4.5 \%$ to $26 \%$ [34]. Furthermore, MG infection can persist for a long time in the female genital tract $[33,31,35]$. Thus, it is plausible to conclude that vaginal sexual intercourse is a major route of transmission for MG. Perhaps, MSMs with bisexual behaviors is a sub-population with higher risk for MG infection. It was previously reported that more than one-third of MSMs in China were married to women, and more than $70 \%$ of heterosexual behaviors were unprotected [36]. Therefore, strengthening the screening of MG among MSM, especially those who had bisexual behaviors, is an important strategy to control this pathogen. In addition, identifying the hidden bisexual MSM with MG infection is helpful for successful HIV/STD control.

The limitations of present study are that reporting bias might exist. Compared with web-based or computerbased questionnaire, the present information-collection method may have less controllability and may be susceptible to misreporting. Besides, we did not distinguish 
between "insertive" and "receptive" anal intercourse among the studied population. Finally, we did not collect data regarding current symptoms and timeframe of sexual partner.

\section{Conclusions}

In this study, we provided MG prevalence at both urethral and rectal sites among the MSM population in Shenzhen, China. We showed that MG was more prevalent in MSMs who had bisexual behaviors compared to those who engaged mainly in homosexual behaviors. It should be noted that there is currently little attention given to MG infection in the National HIV/STD Prevention and Surveillance Guidelines and by health-care providers in China. Further work is needed to establish the mode of MG transmission and to identify its role in HIV transmission. Considering that the MSMs sexually interact with other populations (such as FSWs and the general female population) and therefore acting as a bridge for HIV/STD transmission, paying more attention to MG infection among MSMs, and especially bisexual MSMs, might have important implications for HIV/STD control.

\section{Competing interests}

The authors declare that they have no competing interests.

\section{Authors' contributions}

BJZ, YPY and XSC designed the study and wrote the initial manuscript. NJ and XSC assisted the field work and data collection. YH, MQS, ZX and RXY did the laboratory test. BJZ and YH did the data analysis. XSC and GYZ edited the manuscript and completed the final revisions. All authors read and approved the final manuscript.

\section{Acknowledgements}

The authors thank Guangdong Provincial Center for Skin Disease and STD Control, and Jiangsu Key Laboratory of Molecular Biology for Skin Diseases and STIs for their collaboration in this study. The authors would especially like to thank the field staff and the study participants who made this survey possible. Special thanks to Ms. Chun Gu and Ms. Jun Liu for their assistance in editing this the manuscript.

This study was funded by the Mega Project of the National Science Research of China for 12 ${ }^{\text {th }}$ Five-Year Plan (2012ZX09301002-005 and 2008ZX10001-005) and by the National Center for STD Control of China.

\section{Author details}

${ }^{1}$ National Center for STD Control, Chinese Academy of Medical Science \& Peking Union Medical College Institute of Dermatology, Nanjing, China. ${ }^{2}$ Reference Laboratory, 12 Jiangwangmiao Street, Nanjing 210042, China.

Received: 12 September 2013 Accepted: 17 February 2014 Published: 21 February 2014

\section{References}

1. Ishihara S, Yasuda M, Ito S, Maeda S, Deguchi T: Mycoplasma genitalium urethritis in men. Int J Antimicrob Agents 2004, 24(Suppl 1):S23-S27.

2. Moi H, Reinton N, Moghaddam A: Mycoplasma genitalium is associated with symptomatic and asymptomatic non-gonococcal urethritis in men. Sex Transm Infect 2009, 85(1):15-18.

3. Manhart LE, Broad JM, Golden MR: Mycoplasma genitalium: should we treat and how? Clin Infect Dis 2011, 53(Suppl 3):S129-S142.

4. Haggerty $\mathrm{CL}$, Taylor BD: Mycoplasma genitalium: an emerging cause of pelvic inflammatory disease. Infect Dis Obstet Gynecol 2011, 2011:959816.
5. McGowin CL, Anderson-Smits C: Mycoplasma genitalium: an emerging cause of sexually transmitted disease in women. PLoS Pathog 2011, 7(5):e1001324

6. Napierala MS, Weiss HA: Association of Mycoplasma genitalium and HIV infection: a systematic review and meta-analysis. AIDS 2009, 23(5):611-620.

7. Francis SC, Kent CK, Klausner JD, Rauch L, Kohn R, Hardick A, Gaydos CA: Prevalence of rectal Trichomonas vaginalis and Mycoplasma genitalium in male patients at the San Francisco STD clinic, 2005-2006. Sex Transm Dis 2008, 35(9):797-800.

8. Vandepitte J, Muller E, Bukenya J, Nakubulwa S, Kyakuwa N, Buve A, Weiss H, Hayes R, Grosskurth H: Prevalence and correlates of Mycoplasma genitalium infection among female sex workers in Kampala, Uganda. $J$ Infect Dis 2012, 205(2):289-296.

9. Sun X, Wang N, Li D, Zheng X, Qu S, Wang L, Lu F, Poundstone K: The development of HIV/AIDS surveillance in China. AIDS 2007, 21(Suppl 8):S33-S38.

10. Chen XS, Peeling RW, Yin YP, Mabey DC: The epidemic of sexually transmitted infections in China: implications for control and future perspectives. BMC Med 2011, 9:111.

11. Yin YP, Chen SC, Wang HC, Wei WH, Wang QQ, Liang GJ, Jiang N, Han Y, Chen XS, Wang B: Prevalence and risk factors of HSV-2 infection and HSV-2/HIV coinfection in men who have sex with men in China: a multisite cross-sectional study. Sex Transm Dis 2012, 39(5):354-358.

12. Jensen JS, Bjornelius E, Dohn B, Lidbrink P: Use of TaqMan 5' nuclease real-time PCR for quantitative detection of Mycoplasma genitalium DNA in males with and without urethritis who were attendees at a sexually transmitted disease clinic. J Clin Microbiol 2004, 42(2):683-692.

13. Xiang Z, Yin YP, Shi MQ, Jiang N, Han Y, Wang HC, Zheng BJ, Liang GJ, Chen XS: Risk factors for Mycoplasma genitalium infection among female sex workers: a cross-sectional study in two cities in southwest China. BMC Public Health 2012, 12(1):414.

14. Bradshaw CS, Fairley CK, Lister NA, Chen SJ, Garland SM, Tabrizi SN: Mycoplasma genitalium in men who have sex with men at male-only saunas. Sex Transm Infect 2009, 85(6):432-435.

15. Soni S, Alexander S, Verlander N, Saunders P, Richardson D, Fisher M, Ison C: The prevalence of urethral and rectal Mycoplasma genitalium and its associations in men who have sex with men attending a genitourinary medicine clinic. Sex Transm Infect 2010, 86(1):21-24.

16. Reinton N, Moi H, Olsen AO, Zarabyan N, Bjerner J, Tonseth TM, Moghaddam A: Anatomic distribution of Neisseria gonorrhoeae Chlamydia trachomatis and Mycoplasma genitalium infections in men who have sex with men. Sex Health 2013, 10(3):199-198.

17. Kent CK, Chaw JK, Wong W, Liska S, Gibson S, Hubbard G, Klausner JD: Prevalence of rectal, urethral, and pharyngeal chlamydia and gonorrhea detected in 2 clinical settings among men who have sex with men: San Francisco, California, 2003. Clin Infect Dis 2005, 41(1):67-74.

18. Lister NA, Smith A, Tabrizi S, Hayes P, Medland NA, Garland S, Fairley CK: Screening for Neisseria gonorrhoeae and Chlamydia trachomatis in men who have sex with men at male-only saunas. Sex Transm Dis 2003, 30(12):886-889.

19. Benn PD, Rooney G, Carder C, Brown M, Stevenson SR, Copas A, Robinson AJ, Ridgway GL: Chlamydia trachomatis and Neisseria gonorrhoeae infection and the sexual behaviour of men who have sex with men. Sex Transm Infect 2007, 83(2):106-112.

20. Vodstrcil LA, Fairley CK, Fehler G, Leslie D, Walker J, Bradshaw CS, Hocking JS: Trends in chlamydia and gonorrhea positivity among heterosexual men and men who have sex with men attending a large urban sexual health service in Australia, 2002-2009. BMC Infect Dis 2011, 11:158.

21. Manhas A, Sethi S, Sharma M, Wanchu A, Kanwar AJ, Kaur K, Mehta SD: Association of genital mycoplasmas including Mycoplasma genitalium in HIV infected men with nongonococcal urethritis attending STD \& HIV clinics. Indian J Med Res 2009, 129(3):305-310.

22. Ballard RC, Fehler HG, Htun Y, Radebe F, Jensen JS, Taylor-Robinson D: Coexistence of urethritis with genital ulcer disease in South Africa: influence on provision of syndromic management. Sex Transm Infect 2002, 78(4):274-277.

23. Chen XS, Yin YP, Jiang N, Wang B: Setting typologies and HIV prevalence among men who have sex with men in China: implication for surveillance and intervention. Sex Transm Dis 2012, 39(3):226-228. 
24. Gao L, Zhang L, Jin Q: Meta-analysis: prevalence of HIV infection and syphilis among MSM in China. Sex Transm Infect 2009, 85(5):354-358.

25. Jian-Ru W, Bei W, Hao C, Jin-Shui X, Xi-Ping H: Mycoplasmas in the urine of HIV-1 infected men. Epidemiol Infect 2011, 140(6):1141-1146.

26. Savio ML, Caruso A, Allegri R, Fallacara F, Pollara CP, Foresti I, Comberti E, Gargiulo F, Dima F, Cadeo GP, Turano A: Detection of Mycoplasma genitalium from urethral swabs of human immunodeficiency virusinfected patients. New Microbiol 1996, 19(3):203-209.

27. Mavedzenge SN, Van Der Pol B, Weiss HA, Kwok C, Mambo F, Chipato T, Van der Straten A, Salata R, Morrison C: The association between Mycoplasma genitalium and HIV-1 acquisition in African women. AIDS 2012, 26(5):617-624.

28. Li HM, Peng RR, Li J, Yin YP, Wang B, Cohen MS, Chen XS: HIV incidence among men who have sex with men in China: a meta-analysis of published studies. PLoS One 2011, 6(8):e23431.

29. Mezzini TM, Waddell RG, Douglas RJ, Sadlon TA: Mycoplasma genitalium: prevalence in men presenting with urethritis to a South Australian public sexual health clinic. Int Med J 2013, 43(5):494-500.

30. Bradshaw CS, Tabrizi SN, Read TR, Garland SM, Hopkins CA, Moss LM, Fairley CK: Etiologies of nongonococcal urethritis: bacteria, viruses, and the association with orogenital exposure. J Infect Dis 2006, 193(3):336-345.

31. Oakeshott P, Aghaizu A, Hay P, Reid F, Kerry S, Atherton H, Simms I, Taylor-Robinson D, Dohn B, Jensen JS: Is Mycoplasma genitalium in women the "New Chlamydia?" A community-based prospective cohort study. Clin Infect Dis 2010, 51(10):1160-1166.

32. Tsunoe H, Tanaka M, Nakayama H, Sano M, Nakamura G, Shin T, Kanayama A, Kobayashi I, Mochida O, Kumazawa J, Naito S: High prevalence of Chlamydia trachomatis, Neisseria gonorrhoeae and Mycoplasma genitalium in female commercial sex workers in Japan. Int J STD AIDS 2000, 11(12):790-794.

33. Cohen CR, Nosek M, Meier A, Astete SG, Iverson-Cabral S, Mugo NR, Totten PA: Mycoplasma genitalium infection and persistence in a cohort of female sex workers in Nairobi, Kenya. Sex Transm Dis 2007, 34(5):274-279.

34. Weinstein SA, Stiles BG: A review of the epidemiology, diagnosis and evidence-based management of Mycoplasma genitalium. Sex Health 2011, 8(2):143-158.

35. Blaylock MW, Musatovova O, Baseman JG, Baseman JB: Determination of infectious load of Mycoplasma genitalium in clinical samples of human vaginal cells. J Clin Microbiol 2004, 42(2):746-752.

36. Lau JT, Wang M, Wong HN, Tsui HY, Jia M, Cheng F, Zhang Y, Su X, Wang N Prevalence of bisexual behaviors among men who have sex with men (MSM) in China and associations between condom use in MSM and heterosexual behaviors. Sex Transm Dis 2008, 35(4):406-413.

doi:10.1186/1471-2458-14-195

Cite this article as: Zheng et al:: The prevalence of urethral and rectal Mycoplasma genitalium among men who have sex with men in China, a cross-sectional study. BMC Public Health 2014 14:195.

\section{Submit your next manuscript to BioMed Central and take full advantage of:}

- Convenient online submission

- Thorough peer review

- No space constraints or color figure charges

- Immediate publication on acceptance

- Inclusion in PubMed, CAS, Scopus and Google Scholar

- Research which is freely available for redistribution 